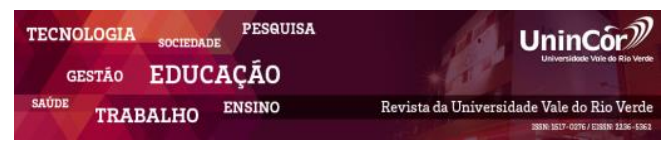

Revista da Universidade Vale do Rio Verde ISSN: 1517-0276 / EISSN: 2236-5362 v. 17 | n. 1 | Ano 2019

Ferdinando Vitor Esperidião Graduação Tecnológica em Logística pela UninCor - Universidade Vale do Rio Verde. E-mail: ferdiskate@hotmail.com

Marina Natiele Nascimento de Souza Graduação Tecnológica em Logística pela UninCor - Universidade Vale do Rio Verde.

E-mail: marinanatiele17@hotmail.com

Milla Crislaine da Silva Graduação Tecnológica em Logística pela UninCor - Universidade Vale do Rio Verde.. E-mail: milla_crislaine@yahoo.com

Samuel Carvalho dos Santos Professor Orientador da UNINCOR -

Universidade Vale do Rio Verde.

E-mail: prof.samuel.santos@ unincor.edu.br

\section{A UTILIZAÇÃO DE APLICATIVOS \\ COMO FACILITADOR DENTRO DO \\ PROCESSO LOGÍSTICO}

\section{RESUMO}

A logística empresarial hoje, faz parte das atividades cruciais de uma organização que pretenda se manter competitiva no mercado. A grande competitividade e o crescimento das organizações, têm evidenciado as empresas a uma demanda por competências no atendimento de suas necessidades. A utilização de tecnologias no apoio do processo logístico vem sendo utilizado como uma grande parceira para a otimização dos processos e melhoria do nível de serviço. Com isso, o presente artigo tem como objetivo principal o desenvolvimento de um aplicativo que tenha como função o auxílio das atividades logísticas divididas em dez passos desde a entrada de matéria prima na empresa tendo relação com o processo de fabricação até a entrega do produto acabado no cliente. A metodologia utilizada neste trabalho se consistiu de pesquisas em artigos científicos já publicados, relacionados a Tecnologia da Informação e sua importância nos processos Logísticos, criação e desenvolvimento de aplicativos e aplicativos para celular. Pesquisou-se também em livros e revistas com enfoque na Logística, administração de materiais, gestão da cadeia de distribuição e vantagem competitiva. Os aplicativos são um meio estratégico e tático de empreender os negócios, criados na maioria, especificamente para facilitar e descomplicar o cotidiano dos clientes numa visão empresarial. Por meio de tudo o que foi estudado observa-se que a tecnologia de aplicativos aliada a logística contribuirá muito para o desenvolvimento das organizações e fará com que a mesma se torne um diferencial competitivo perante às demais que estarão no mesmo segmento.

Palavras-chave: AAP's. Logística. Tecnologia. Informação. Diferencial Competitivo.

\section{THE USE OF APP'S AS A FACILITATOR WITHIN THE LOGISTICAL PROCESS}


the company having relation with the manufacturing process until the delivery of the finished product in the client. The methodology used in this work consisted of research in scientific articles already published, related to Information Technology and its importance in Logistics processes, creation and development of applications and applications for mobile. It has also been researched in books and magazines focusing on Logistics, materials management, distribution chain management and competitive advantage. Applications are a strategic and tactical means of undertaking business, created in the majority, specifically to facilitate and uncomplicate the daily routine of customers in a business perspective. Through all that has been studied it is observed that the technology of applications allied with logistics will contribute a lot to the development of the organizations and will make it become a competitive differential before the others that will be in the same segment.

Keywords: AAP's. Logistics. Technology. Information. Competitive Differential.

Recebido em: 28/12/2018 - Aprovado em: 10/04/2019 - Disponibilizado em: 15/07/2019

\section{INTRODUÇÂO}

A Logística é a área da gestão incumbida de fornecer equipamentos, informações e recursos para todas as atividades de uma empresa. Pode-se dizer que a logística é uma sub-área da Administração, envolvendo diversos recursos da engenharia, economia, contabilidade, estatística, marketing e tecnologia do transporte e dos recursos humanos.

A Logística tem obtido um grande avanço no decorrer dos anos, a globalização tem grande influência sobre este fato. Os processos logísticos estão se tornando partes essenciais dentro do âmbito empresarial, fazendo com que a competitividade entre as organizações cresça.

Com o passar dos anos, surge a necessidade de se produzir mais, conhecer mais, ter mais informações e em tempo hábil. Caminhando lado a lado com estas características estão os smartphones, celulares que fazem muito mais do que só realizar chamadas telefônicas ou mandar mensagens de texto. $\mathrm{O}$ desenvolvimento de aplicativos para celular cresce a cada ano e pipocam empresas especializadas no mercado. No entanto, os aparelhos incluindo alguns mais populares, dispõem de bom espaço de armazenamento de aplicativos e também de processadores capazes de executá-los de forma satisfatória.

Engana-se quem acha que o aparelho celular é um dispositivo eletrônico utilizado apenas para transmitir sinal de voz, hoje com a grande tecnologia disponível é comum encontrar aparelhos celulares com poder de processamento igual ou até mesmo superiora computadores do início da década passada, e esses celulares podem rodar aplicativos e jogos. Além dos celulares estarem com alto poder de processamento, as empresas desenvolvem aplicativos cada vez mais familiarizados com seus usuários e desta forma acabam encantando os donos dos aparelhos. 
Por muito tempo as mídias tradicionais foram o foco para os anunciantes, porém, está hegemonia está sendo ameaçada, pois segundo Cavalini (2008) a tecnologia oferece ferramentas, criação de novas possibilidades pelos próprios usuários. $\mathrm{E}$ as mesmas se tornam útil na Logística, suas aplicações e estratégias.

Hoje os telefones celulares possuem tecnologia de ponta. Esta tecnologia tem feito as pessoas se aproximarem ainda de seus gadgets. As várias versões de aparelhos e aplicativos faz com que a evolução tecnológica acabe deixando as pessoas atordoadas quando tentam acompanhar a tecnologia que evolui quase que diariamente. A Logística é uma área de grande importância para a evolução da humanidade. Pensando nisto surge a ideia de desenvolver um aplicativo para smartphone que possa ajudar a gerir a logística. Como os aplicativos fazem cálculos de modo rápido, possuem a opção de localização geográfica, tem desempenho considerável, porque não usá-los na administração da logística unindo o útil ao agradável?

Pretende-se no decorrer deste trabalho propor o desenvolvimento de um aplicativo que tenha como função principal o auxílio das atividades logísticas, onde o mesmo teria um banco de dados que informaria em tempo real ou o mais verídico possível os processos logísticos. Com este aplicativo, operadores logísticos, clientes e até mesmo fornecedores poderão estar informados e/ou informarem, por exemplo, desde o processo de fabricação até a entrega do produto e/ou serviços aos clientes.

\section{2 -REVISÃO DE LITERATURA}

De acordo com Silva (2014), a evolução da tecnologia dos aparelhos celulares permitiu oferecer ao usuário recursos que vão muito além da realização de uma chamada ou do envio de uma mensagem. Hoje, com a grande tecnologia disponível é comum encontrar aparelhos celulares com poder de processamento igual ou até mesmo superior a computadores do início da década passada

\section{1 - UM BREVE HISTÓRICO DOS APLICATIVOS PARA CELULAR}

Os aplicativos são criados com o objetivo de facilitar o desempenho de atividades práticas dos usuários ou meramente por divertimento (RODRIGUES, 2012).

Um dos sistemas operacionais para smartphones e tablets mais populares no Brasil é o Android. Segundo Cardoso (2012) Android era apenas o nome de uma pequena empresa de software fundada em 2003 na Califórnia, EUA. Após dois anos a Google comprou esta empresa, contratando seus principais desenvolvedores.

Em 2008 a Google lança sua primeira versão de sistema operacional móvel, o Android 1.0. Desde então seu uso cresceu e em 4 anos os americanos somavam $50 \%$ dos assinantes de smartphones nos EUA (CARDOSO 2012).

Para Pereira (2009), Android é uma plataforma para tecnologia móvel completa, envolvendo um pacote com programas para celulares, já com um sistema operacional, middleware, aplicativos e interface do usuário. 
Para criar um aplicativo para o sistema Android e necessário instalar e configurar um conjunto de ferramentas que inclui o Java SE Development Kit (JDK), um ambiente de desenvolvimento, o Android Software Development Kit (SDK) e o AndroidDevelopment Tools (ADT) (CARDOSO, 2012).

O desenvolvimento de aplicativos para Android podem ser feitos usando um Mac, um computador com Windows ou um computador com Linux. O Android e open source e tem como base o Kernel do Linux, o que significa que pode ser alterado livremente. Por ser um código livre, todas as ferramentas necessárias para o desenvolvimento de um aplicativo Android são gratuitas e estão disponíveis para download na Internet, facilitando o desenvolvimento de novos aplicativos (CARDOSO, 2012).

Sabe-se que os aplicativos para os smartphones contribuíram para o sucesso desses dispositivos móveis (CARDOSO, 2012).

Os aplicativos apresentam propriedades interessantes para atrair a atenção do consumidor, como a geração de uma ambiência, a livre escolha do usuário em fazer o download do software, a interação proporcionada pela conexão com as redes sociais e o apelo multissensorial, aguçado pelo envolvimento tátil com a tela touchscreen dos smartphones (ALVES, 2016).

No Brasil, o mercado de aplicativos movimenta cerca de US\$ 25 bilhões por ano e, segundo projeções do Ministério da Ciência, Tecnologia e Inovação (MCTI), o montante deve chegar a US\$ 70 bilhões em 2017 (ALVES, 2016).
Com o passar do tempo há uma necessidade de se evoluir, já que a evolução em sistemas acontece de forma exponencial e não linear. Ou seja, a tecnologia embargada em celulares e dispositivos móveis deve ser atualizada rapidamente.

\section{2 - LOGÍSTICA}

Segundo Ballou (2006) a logística inclui todas as atividades importantes para a disponibilização de bens e serviços aos consumidores quando e onde estes quiserem adquiri-los.

A logística é um diferencial competitivo e com isso cada dia mais é utilizada como um planejamento estratégico e segundo Porter (2006, p. 52) “O lema estratégia é ser diferente. Significa escolher, de forma deliberada, um conjunto diferente de atividades para proporcionar um mix único de valores. ”

E para Stoner (1994, p. 136) "deve-se pensar que o planejamento é a locomotiva que puxa o trem das ações de organizar, liderar e controlar".

Com isso a logística se torna cada vez mais informatizada. As novas tecnologias não somente mudam o ambiente como também ajudam a ser competitivos, e a logística tem que se valer da TI como uma arma competitiva, a qual se torna um pré-requisito para o sucesso (CLOSS, 1997)

Para Wang (1998) a informação tecnológica pode ser a maior ferramenta dos 
tempos modernos, mas é o julgamento de negócios dos humanos que a faz poderosa.

A Logística evolui diariamente e com isso seus conceitos e preceitos se desenvolvem e abrangem cada vez mais.

Por isso deve-se alinhar ou melhor devese unir as atividades logísticas com a informação tecnológica para cada dia mais conseguirmos clientes mais satisfeitos e rendimentos compensatórios a empresa.

\section{3- MATERIAL E MÉTODOS}

A metodologia utilizada neste trabalho se consistiu de pesquisas em artigos científicos já publicados, relacionados a Tecnologia da Informação e sua importância nos processos Logísticos, criação e desenvolvimento de aplicativos e aplicativos para celular. Pesquisouse também em livros e revistas com enfoque na Logística, administração de materiais, gestão da cadeia de distribuição e vantagem competitiva. Todos estes colaboraram para a criação e desenvolvimento deste artigo.

\section{4 - DESENVOLVIMENTO}

Em meados do ano de 1997, a Nokia foi a primeira empresa a perceber que os celulares poderiam fazer muito mais que chamadas. Além de introduzir o conceito de SMS (as mensagens ou torpedos), ela inovou ao lançar jogos simples que fizeram muito sucesso na época, como o popular SNAKE que, ainda hoje, alguns saudosos mantem como aplicativos em seus modernos smartphones.
Em 2002, os primeiros celulares com linguagem de programação JAVA chegaram ao mercado e as empresas e usuários começaram a criar aplicativos e jogos para a plataforma mobile. De 2003 a 2006, a evolução foi dos aparelhos. Com a tela colorida e maior capacidade de armazenamento e processamento, os jogos, que antes tinham $30 \mathrm{~KB}$, passam a ter $1 \mathrm{MB}$ ou mais. Assim, as empresas de jogos como a Capcom, Namco, Disney, Konami e ElectronicArts, começaram a marcar presença nesse mercado.

Os primeiros Smartphones:

Em 1994, foi lançado pela IBM Simon, um telefone que fazia muitas das funções de um Smartphone, mas que ainda não era conhecido como tal. O telefone era muito além do seu tempo, já trazendo características muito comuns aos celulares atuais, como a tela sensível ao toque (touchscreen), calendário, conta de e-mail e bloco de notas. Não fez grande sucesso. A Ericson lançou em 1997 o GS88 e legitimou pela primeira vez o termo SMARTPHONE. Entretanto, o Smartphone que fez jus ao nome foi o Nokia 9000 e depois, seu sucessor com tela colorida, o Nokia 9500 .

Nos últimos anos está ocorrendo uma notável expansão na utilização de dispositivos móveis, que fazem uso da tecnologia de comunicação sem fio, em especial dos telefones celulares. Estes aparelhos apesar do poder computacional limitado, a cada momento possuem uma nova forma, tamanho, aumento na capacidade de processamento, além de novos aplicativos agregados. 
À medida que a demanda por funcionalidades cresce, as empresas de telefonia celular acrescentam novas tecnologias a tais aparelhos, estimulando nos consumidores o desejo de possuir o mais recente modelo de uma determinada marca.

Os celulares começaram a adquirir novas e mais modernas características, deixando de servir simplesmente para telefonia, ou seja, a mera transmissão de voz está perdendo o espaço para transmissão de dados.

Os aplicativos são criados com o objetivo de facilitar o desempenho de atividades práticas dos usuários ou meramente por divertimento (RODRIGUES, 2012).

Um dos sistemas operacionais para smartphones e tablets mais populares no Brasil é o Android. Segundo Cardoso (2012) Android era apenas o nome de uma pequena empresa de software fundada em 2003 na Califórnia, EUA. Após 2 anos a Google comprou esta empresa, contratando seus principais desenvolvedores.

Em 2008 a Google lança sua primeira versão de sistema operacional móvel, o Android 1.0. Desde então seu uso cresceu e em 4 anos os americanos somavam 50\% dos assinantes de smartphones nos EUA (CARDOSO, 2012).

Para Pereira (2009), Android é uma plataforma para tecnologia móvel completa, envolvendo um pacote com programas para celulares, já com um sistema operacional, middleware, aplicativos e interface do usuário.

Para criar um aplicativo para o sistema Android e necessário instalar e configurar um conjunto de ferramentas que inclui o Java SE
Development Kit (JDK), um ambiente de desenvolvimento, o Android Software Development Kit (SDK) e o AndroidDevelopment Tools (ADT) (CARDOSO, 2012).

O desenvolvimento de aplicativos para Android podem ser feitos usando um Mac, um computador com Windows ou um computador com Linux. O Android e open source e tem como base o Kernel do Linux, o que significa que pode ser alterado livremente. Por ser um código livre, todas as ferramentas necessárias para o desenvolvimento de um aplicativo Android são gratuitas e estão disponíveis para download na Internet, facilitando o desenvolvimento de novos aplicativos (CARDOSO, 2012).

Sabe-se que os aplicativos para os smartphones contribuíram para o sucesso desses dispositivos móveis (CARDOSO, 2012).

Os aplicativos apresentam propriedades interessantes para atrair a atenção do consumidor, como a geração de uma ambiência, a livre escolha do usuário em fazer o download do software, a interação proporcionada pela conexão com as redes sociais e o apelo multissensorial, aguçado pelo envolvimento tátil com a tela touchscreen dos smartphones (ALVES, 2016).

No Brasil, o mercado de aplicativos movimenta cerca de US\$ 25 bilhões por ano e, segundo projeções do Ministério da Ciência, Tecnologia e Inovação (MCTI), o montante deve chegar a US\$ 70 bilhões em 2017(ALVES, 2016).

Com o passar do tempo há uma necessidade de se evoluir, já que a evolução em sistemas acontece de forma exponencial e não 
linear. Ou seja, a tecnologia embargada em celulares e dispositivos móveis deve ser atualizada rapidamente.

Logo, a criação dos aplicativos se deu pela necessidade tanto pessoal quanto profissional de agilidade nos processos diários e na maioria das vezes pela praticidade que os mesmos oferecem.

O aplicativo para celular, também chamado de app, tem várias funções para o aparelho e para o usuário. Hoje em dia já existem milhares destes programas para atender o público cada vez mais exigente. Aplicativos para aparelhos celulares têm se tornado cada vez mais completos e complexos. Eles conseguem atingir a particularidade de cada pessoa, alguns parecem que sabem exatamente o que o usuário precisa em certos momentos. Um bom exemplo de aplicativos mais populares são os de geolocalização, aplicativos estes que ajudam a pessoa a se localizar e a encontrar algum lugar de seu interesse. $\mathrm{O}$ celular possuindo sinal, a pessoa consegue encontrar endereços diversos, marcar suas preferências, fugir de rotas mais congestionadas e até sair do país.

De acordo com Silva (2014), a evolução da tecnologia dos aparelhos celulares permitiu oferecer ao usuário recursos que vão muito além da realização de uma chamada ou do envio de uma mensagem. Hoje, com a grande tecnologia disponível é comum encontrar aparelhos celulares com poder de processamento igual ou até mesmo superior a computadores do início da década passada.
Mediante a realidade demandada por serviços e recursos móveis, começam a surgir no mercado sites desenvolvidos para promover a liberdade no uso e consumo de informações por parte dos usuários finais que adquirem aparelhos como os smartphones que possuem facilidade de uso e recursos cada vez mais modernos.

Muitos sites e soluções para internet atualmente já tem como foco sua compatibilidade com dispositivos móveis. Assim o uso da internet através dos Smartphones difere do uso no computador de mesa e notebook sob vários aspectos. Na verdade, A diferença é uma das vantagens, consiste em não necessitar de um computador com teclado e mouse conectados fisicamente. Por meio do uso dos dispositivos móveis, a liberdade de locomoção com acesso a internet é o ponto positivo que desperta o interesse dos usuários finais e atração comercial dos publicitários. A mobilidade assim permite ter em mãos serviços, informações, comunicação e entretenimento. No caso dos serviços incluem as transações bancárias, previsões do tempo, notícias e serviços de rastreio de encomendas ou veículos.

No universo dos aplicativos, temos vários tipos. Para todos os gostos e classes. Os aplicativos atendem desde o jovem que quer se conectar até o empresário que precisa trabalhar pelo celular. Os tipos mais comuns são:

Serviços: fornecem informações e conteúdo de modo simplificado e ágil, como aplicativos para previsões do tempo, navegação de mapas ou até solicitar um resgate à seguradora do seu carro, por exemplo. 
Informações: acesso a conteúdos atualizados em tempo real ou que têm utilidade permanente, como guias de compras/lojas, telefones úteis, promoções, consulta de produtos, entre outros.

Comunicação: permitem a conexão entre pessoas, como o Skype, Msn, ou aplicativos de integração com as redes sociais.

Entretenimento: destinado para diversão. A industria de jogos é a que tem maior faturamento entre todos os segmentos do entretenimento. Os aplicativos favorecem ainda mais esse crescimento, pois permitem uma integração perfeita com os jogos.

Como vantagens dos aplicativos de celular podemos citar a facilidade de uso, eles possibilitam melhor experiência para uso de recursos e interface dos dispositivos, otimizando a navegação e a agilidade das ações. $\mathrm{O}$ menor custo de acesso, como a interface é adaptada para o dispositivo, o tráfego de dados necessários para navegação é muito menor se comparado ao uso de navegadores convencionais. O melhor uso dos recursos disponíveis: Os aplicativos possibilitam melhor experiência com os recursos que o aparelho possui como GPS, câmera fotográfica, bluetooth, entre outros. Acesso off-line: muitos aplicativos armazenam informações que possibilitam navegação mesmo sem acesso à internet. É possível uma empresa vender bens, conteúdos e acessos premium dentro dos aplicativos.

Já como desvantagens dos aplicativos de celular podemos citar: Atualização de versões: com o lançamento de novos modelos de smartphones e tablets, os sistemas operacionais melhoram e permitem novas possibilidades aos aplicativos. Porém, só tem acesso quem possuir as novas versões isso faz com que um iPad 1, por exemplo, seja muito limitado em questão de aplicativos, pois muitos não poderão ser instalados devido a versão ultrapassada do tablet. Solução? Sempre comprar modelos novos (o que não será nada barato...). Temos também como desvantagem o problema de se ter plataformas diferentes: cada marca possui sua própria plataforma de aplicativos, portanto, escolher a fabricante do seu novo dispositivo determina a quantidade e diversidade de aplicativos que você poderá utilizar.

A logística é uma expressão que surgiu há alguns anos, e vem evoluindo ao longo do tempo, sendo muito utilizada e analisada nos meios empresariais atuais, como um processo de planejamento, implementação e controle de forma eficiente e eficaz com a principal função diminuir os custos de produção, produtos e serviços para melhor servir os clientes cada vez mais exigente, agregando valor aos mesmos.

O conceito de logística vem sido melhorado por vários anos, e com isso as empresas e instituições percebendo a importância da mesma e de mantê-la atual e eficiente, estão investindo na capacitação de seus colaboradores, fomentando competitividade frente ao mercado.

A logística é diferencial competitivo e com isso cada dia mais é utilizada como um planejamento estratégico e segundo Porter (2006, p. 52) "O lema estratégia é ser diferente. Significa escolher, de forma deliberada, um conjunto diferente de atividades para proporcionar um mix 
único de valores". Com isso operadores logísticos e todos os profissionais que trabalham na área de logística tem que ter uma visão holística para atender e prever adversidades que possam ocorrer durante o processo.

Com isso a logística se torna cada vez mais informatizada. As novas tecnologias não somente mudam o ambiente como também ajudam a ser competitivos, e a logística tem que se valer da TI como uma arma competitiva, a qual se torna um pré-requisito para o sucesso (CLOSS, 1997).

\section{Para Wang (1998) a informação} tecnológica pode ser a maior ferramenta dos tempos modernos, mas é o julgamento de negócios dos humanos que a faz poderosa.

A Logística evolui diariamente e com isso seus conceitos e preceitos se desenvolvem e abrangem cada vez mais caminhos e meios deferentes.

Por isso deve-se alinhar, ou melhor, devese unir as atividades logísticas com a informação tecnológica para conseguir clientes mais satisfeitos e rendimentos compensatórios a empresa.

Contudo diante da velocidade de informação o surgimento e a renovação das tecnologias existentes, e a constante exigência dos clientes é necessário buscar a inovação e realização de planejamento de processos logísticos para poder entender e atender as necessidades que o mercado está mostrando, a fim de satisfazer ao máximo aos anseios dos clientes e colaboradores.
Para que todo planejamento logístico funcione com mais dinamismo são necessários o auxílio e a intervenção da tecnologia da informação. Os aplicativos, por sua vez, possibilitam a integração interna das empresas como, também, com seus parceiros externos permitindo a gestão centralizada das movimentações, estoques e informação entre diferentes organizações (RUTNER, 2000).

Com este pensamento através deste artigo é proposto o desenvolvimento de um aplicativo que tenha como função principal o auxílio das atividades logísticas por meio de um banco de dados que informaria em tempo real ou o mais real possível os processos logísticos. Por meio do mesmo os operadores logísticos poderiam por exemplo obter informação de alguma rota que está interditada ou que em certo trecho tem muita neblina, entre outros. Este aplicativo poderia ser integrado a polícia rodoviária para se ter informações mais precisas das condições adversas que a rota possa estar naquele momento.

O aplicativo tornaria mais ágil a resposta e feedback tanto a colaboradores da empresa quanto ao consumidor final, que tanto espera e anseia por seu produto. Resposta esta que se tornaria cada da vez mais um diferencial uma vez que o tempo de resposta seria diminuído, garantindo assim a satisfação de todos.

Segue abaixo uma ideia das divisões desse aplicativo: 1) Aviso matéria prima, 2) Produção, 3) Controle de produção, 4). Retrabalho, 5). Descarte, 6). Aprovado, 7) Estoque, 8) Expedição, 9) Posição geográfica, 10) Entrega. 
No momento 01 o aplicativo avisa o usuário, seja ele interno ou externo, que tipo de matéria prima vai entrar em produção, suas características, lote e quantidade. No momento 02 o programa avisa o que foi produzido, quanto foi produzido e quem quanto tempo foi produzido. Após os testes de qualidade, aviso 03, o produto pode ser encaminhado ao retrabalho ou ao descarte. No caso de ser aprovado o aplicativo recebe o aviso do que foi produzido e quanto foi produzido. Após esta ação o produto é encaminhado para o estoque já contado e conferido. $\mathrm{O}$ produto saindo do estoque avisa o aplicativo (momento $\mathrm{n}^{\circ} 7$ ) a quantidade e tipos de produtos que irão para a expedição. Saindo da expedição ele avisa o programa (aviso 08 ) sobre o endereço de destino, a posição atual, o horário que está saindo e a previsão de entrega. No Aviso 09, ele apresenta sua posição geográfica recalculando o tempo de entrega. No aviso 10 ele atualiza o sistema indicando a hora da entrega e se a encomenda chegou em boas condições.

\section{5 -CONSIDERAÇÕES FINAIS}

É notório que a tecnologia já faz parte do cotidiano de todo mundo. Com a evolução, ela deixou de ser um luxo para ser uma necessidade. Hoje, as pessoas que não fazem uso da tecnologia (se é que ainda exista alguém), ficam isoladas ou se sentem acanhadas. $\mathrm{O}$ uso de aplicativos para celular cresce absurdamente a cada dia. $\mathrm{O}$ uso intenso das redes sociais em celulares já ficou evidente. Com isso tem-se a ideia de usar a tecnologia embargada nos aplicativos para celular para atuar no mercado. Muitas são as áreas que se interessam a usar os aplicativos, já que a variedade de funções deles é enorme.

A área da logística já possui muitos programas de computador e celular voltados para controle e execução de algumas tarefas, porém nada ainda muito funcional.

Constata-se que para ter êxito nas atividades logísticas, tanto na produção quanto no serviço, é necessário investir de forma eficaz na tecnologia, garantindo dados e informações rápidos. $\mathrm{O}$ consumidor dos dias atuais, mais do que nunca determina que seus pedidos tenham um feedback urgente. A TI atende este objetivo, auxiliando para a racionalização das tarefas e sincronização das atividades, resultando em uma maior eficiência.

A tecnologia tem feito com que as empresas sejam auto selecionadas entre si na sociedade, quanto mais se interessam em estar à frente no mercado, mais se importam em modernizar e tornar flexível seus processos. Consequentemente, destacam-se das outras com respostas ágeis.

Os aplicativos são um meio estratégico e tático de empreender os negócios, criados na maioria, especificamente para facilitar e descomplicar o cotidiano dos clientes numa visão empresarial. Isso também se dá no meio organizacional, onde com um aplicativo os métodos e procedimentos de cada tarefa logística são executadas num tempo menor, comparado a uma tarefa manual. Os mesmos trazem consigo as vantagens da redução de tempo na produção, facilidade de acesso a informações, menor custo 
de acesso ao aplicativo e desfrute de outros recursos avançados.

\section{REFERÊNCIAS}

ALVES, Daniele de Castro. Aplicativos para celular: Mobilidade, entretenimento e novos hábitos de consumo na relação com a marca. Trama Indústria Criativa em Revista. Dossiê: Mobilidades e Cotidianos. Ano 1, v. 1, Jan - Jul de 2016.

BALLOU, Ronald H. Gerenciamento da cadeia de suprimentos: planejamento, organização e logística empresarial. 5.ed. Porto Alegre: Bookmann, 2006. 609p.

CARDOSO, André Specian. Avaliação de aplicações gráficas em diferentes versões do sistema Android. Cascavel, Curso de Bacharelado em Ciência da Computação, UNIOESTE - Universidade Estadual do Oeste do Paraná. 2012.

CLOSS, David J. Information technology influences on world class logistics capability. International Journal of Physical Distribution \& Logistics Management, v.27, n.1, p. 417.1997

PEREIRA, Lúcio CamilioOliva; Android para Desenvolvedores. Rio de Janeiro, Ciência Moderna, 2009. 240p.

PORTER, Michael E. Vantagem Competitiva: Criando e Sustentando um Desempenho Superior. $35^{\mathrm{a}}$ reimpressão. Rio de Janeiro: ed. Elsevier, 2006.

RODRIGUES, Natalia Gabriel. Liberdade na Internet - Utilização de aplicativos para celulares na atividade turística. p02. UFMG Universidade Federal de Minas Gerais. 2012.

RUTNER, S. Logistics Value: definition, process and measurement", InternationalJournal of Logistics Management; v. 11, no 2; p. $73-82$, 2000.

SILVA, Marcelo Moro da; SANTOS, Marilde Terezinha Prado. Os paradigmas de desenvolvimento de aplicativos para aparelhos celulares. São Carlos, v. 3, n. 2, p. 162-170, maiago 2014 - Tecnologia, Infraestrutura e Software.

STONER, James A. F; FREEMAN, R. Edward. Administração: Rio de Janeiro: ed. LTC, 1994. 560p.

WANG, Charles B. Techno vision II: um guia para profissionais e executivos dominarem a tecnologia e internet. São Paulo: Makron Books. 1998. 190p.

Ferdinando Vitor Esperidião

Graduação Tecnológica em Logística pela UninCor - Universidade Vale do Rio Verde.

\begin{tabular}{l}
\hline Marina Natiele Nascimento de Souza \\
Graduação Tecnológica em Logística pela UninCor \\
- Universidade Vale do Rio Verde.
\end{tabular}

Milla Crislaine da Silva

Graduação Tecnológica em Logística pela UninCor - Universidade Vale do Rio Verde.

\footnotetext{
Samuel Carvalho dos Santos

Mestre em Educação pela UNIVÁS - Universidade Vale do Sapucaí; MBA em Administração, Finanças e Negócios pela Universidade Candido Mendes UCAM; Pós Graduação em Gestão de Pessoas e Projetos Sociais pela Universidade Federal de Itajubá - UNIFEI; MBA em Planejamento e Gestão Estratégica pela UNINTER; Graduação em Processos Gerenciais pelo Centro Universitário do Sul de Minas, UNIS
} 